\title{
The effect of guar gum on carbohydrate-, fat- and protein-stimulated gut hormone secretion: modification of postprandial gastric inhibitory polypeptide and gastrin responses
}

\author{
By L. M. MORGAN, ${ }^{1}$ J. A. TREDGER, ${ }^{2}$ A. MADDEN, ${ }^{2}$ P. KWASOWSKI ${ }^{1}$ \\ AND V. MARKS ${ }^{1}$ \\ Divisions of ${ }^{1}$ Clinical Biochemistry and ${ }^{2}$ Nutrition, Department of Biochemistry, \\ University of Surrey, Guildford, Surrey GU2 $5 X H$
}

(Received 18 June 1984 - Accepted 30 November 1984)

1. The effect of incorporating guar gum into predominantly single-component meals of carbohydrate, fat or protein on liquid gastric emptying and on the secretion of gastric inhibitory polypeptide (GIP), gastrin and motilin, was studied in healthy human volunteers.

2. Volunteers were given either $80 \mathrm{ml} \mathrm{Hycal}$ (carbohydrate meal), 150 g cooked lean minced beef (protein meal) or $200 \mathrm{ml}$ double cream (fat meal) either with or without 5 or $6 \mathrm{~g}$ guar gum. Liquid gastric emptying was monitored in the fat and protein meals by taking $1.5 \mathrm{~g}$ paracetamol, consumed in water, with the meals and monitoring its appearance in circulation.

3. Postprandial insulin and GIP levels were both significantly reduced by addition of guar gum to the carbohydrate meal. Postprandial GIP secretion was also reduced by addition of guar gum to the protein meal, but protein-stimulated gastrin secretion was enhanced by guar gum. There was a significant negative correlation between peak circulating gastrin levels and the corresponding GIP levels. Postprandial GIP secretion and plasma motilin levels were unaffected by addition of guar gum to the fat meal.

4. 5 and $10 \mathrm{~g}$ guar gum $/ 1$ solutions in water possessed buffering capacities between pH $2 \cdot 75$ and $5 \cdot 5$.

5 . Guar gum at $5 \mathrm{~g} / \mathrm{l}$ caused no detectable change in liquid gastric-emptying time.

6. The observed augmentation of gastrin secretion by guar gum following a protein meal could be due either to the buffering capacity of guar gum or to the attenuation of GIP secretion. It is possible that the chronic use of guar gum could be associated with changes in gastric acid secretion.

Guar gum is an unabsorbable carbohydrate derived from the seeds of the Indian cluster bean (Cyamopsis tetragonoloba). When incorporated into a meal it reduces postprandial hyperglycaemia (Jenkins et al. 1976, 1977 a, 1978; Morgan et al. 1979) and has been used successfully as an adjunct therapy for both insulin-dependent and non-insulin-dependent diabetics (Jenkins et al. 1977 b, 1980). Used on a regular daily basis it can also lower plasma cholesterol levels, and has been used in the treatment of patients with hypercholesterolaemia (Jenkins et al. 1979).

The mechanisms by which guar gum exerts its effect on glucose tolerance and circulating cholesterol levels are not yet fully understood. Previous investigations have centred primarily on the effect of guar gum on carbohydrate absorption and metabolism, where it has been shown to slow down the rate of absorption of glucose from the small intestine (Caspary et al. 1980) and to diminish postprandial insulin secretion (Jenkins et al. 1977a). Secretion of the insulin-stimulating gastrointestinal hormone, gastric inhibitory polypeptide (GIP), is also reduced by the addition of guar gum (Morgan et al. 1979) and this reduction has been postulated as being partly responsible for the reduction in insulin secretion observed.

In addition to its insulin-stimulating properties, GIP has the ability to inhibit gastric acid secretion (Brown et al. 1975). Guar gum has also been shown to delay the gastric emptying of a liquid test meal in animals (Leeds et al. 1979; Rainbird et al. 1983, 1984) and in man (Wilmshurst \& Crawley, 1980; Blackburn et al. 1984). Guar gum may exert an effect either directly or indirectly, via changes in GIP, on the secretion of other gastrointestinal 
hormones, namely gastrin and motilin, hormones involved in gastric acid secretion and gastric motility (Christofides et al. 1979a). The effects of guar gum on motilin and gastrin secretion have not previously been studied.

We have therefore investigated the effect of incorporating guar gum with predominantly single-component meals of fat, protein or carbohydrate on the secretion of the gastrointestinal hormones GIP, gastrin and motilin. The effect of guar gum on liquid gastric emptying was also monitored.

\section{MATERIALS AND METHODS}

\section{Clinical studies}

Nineteen healthy male volunteers took part in the study. They were aged between 19 and 35 years and were within $10 \%$ of their ideal body-weight. Each subject gave his informed consent and the study was approved by the Ethical Committees of St Luke's Hospital, Guildford, and the University of Surrey. Subjects attended after an overnight fast on two separate occasions at least 1 week apart and were assigned to one of the test meal protocols.

Carbohydrate meal. Five subjects consumed $80 \mathrm{ml}$ Hycal (Beechams, Brentford) diluted to $250 \mathrm{ml}$ with water. This provided the equivalent of $50 \mathrm{~g}$ glucose in the form of glucose and glucose polymers. On one of the occasions the solution contained $5 \mathrm{~g}$ guar gum (Norgine, London) of a high viscosity grade (O'Connor et al. 1981) which was whisked into it immediately before consumption.

Protein meal. Six subjects were given a meal of $150 \mathrm{~g}$ lean minced beef, providing $30 \mathrm{~g}$ protein and $7 \mathrm{~g}$ fat, either with or without $5 \mathrm{~g}$ guar gum which was incorporated into the meat before cooking. Paracetamol $(1.5 \mathrm{~g})$ was consumed simultaneously on each occasion with $300 \mathrm{ml}$ water and plasma paracetamol levels measured as an index of gastric emptying (Holt et al. 1979).

Fat meal. Eight subjects consumed $200 \mathrm{ml}$ double cream which provided $96 \mathrm{~g}$ fat, $3 \mathrm{~g}$ protein and $4 \mathrm{~g}$ carbohydrate, flavoured with $5 \mathrm{~g}$ Kool Aid (General Foods Corp., New York), a soft-drink flavouring of no nutritional or energy value. Guar gum (6 g) was whisked into the test meal immediately before consumption. In an attempt to provide two meals of a similar consistency, the cream in the control meal was whipped to a firm texture.

Paracetamol $(1.5 \mathrm{~g})$ was consumed with each of the meals, as before, and plasma paracetamol levels measured as an index of gastric emptying.

Venous blood samples were collected from an indwelling venous cannula kept patent with $0 \cdot 123 \mathrm{M}$-sodium citrate whilst the subjects were at rest in the fasted state, and at intervals for 150 or $180 \mathrm{~min}$ from the start of the meals. In the initial experiment (carbohydrate meal), blood was collected for $180 \mathrm{~min}$. As the maximal changes in circulating hormone levels occur between 30 and $100 \mathrm{~min}$, postprandial sampling time was reduced to $150 \mathrm{~min}$ in subsequent experiments.

\section{Chemical analyses}

Blood glucose was measured using a glucose oxidase (EC 1.1.3.4) technique. Immunoreactive plasma insulin, GIP, gastrin and motilin were measured by double-antibody radioimmunoassay techniques (Dryburgh \& Brown, 1975; Morgan et al. 1978) using antibodies supplied by Guildhay Antisera (University of Surrey, Guildford). Plasma triglycerides were measured using a fully enzymic u.v. kit (Boehringer, Mannheim). Plasma paracetamol was measured by high performance liquid chromatography using a $100 \times 5$ mm ODS $\left(\mathrm{C}_{18}\right)$ Hypersil $(5 \mu \mathrm{m})$ column and a running solvent consisting of $0.05 \mathrm{M}$-sodium acetate $(\mathrm{pH} 4.6)$ in methanol $(80: 20, \mathrm{v} / \mathrm{v})$. Benzoic acid was used as an internal standard and the eluate monitored with a u.v. detector at $249 \mathrm{~nm}$. 


\section{Light-scattering index}

Light-scattering indices were measured on a Thorpe Nephalometer (Thorpe Instruments, Cheshire) as an index of postprandial chylomicronaemia.

\section{Buffering capacity of guar gum}

Solutions containing 5 and $10 \mathrm{~g}$ guar gum $/ 1$ in $50 \mathrm{ml}$ water were prepared. The $\mathrm{pH}$ change was measured when they were titrated, in triplicate, against a solution of $0 \cdot 1 \mathrm{M}$-hydrochloric acid and compared with a control of $50 \mathrm{ml}$ water.

\section{Statistical analyses}

Results were compared using Student's $t$ tests for either paired or unpaired data, where appropriate. Areas under the curve were calculated using the trapezoidal rule. $P$ values of $<0.05$ were accepted as statistically significant. Correlation coefficients were calculated by Spearman's rho.

\section{RESULTS}

Carbohydrate meal. Plasma insulin and GIP levels following oral glucose are shown in Fig. 1. Postprandial insulin and GIP levels were both significantly reduced by addition of guar gum to the meal (areas under the plasma insulin curve 0-180 min: 63.3 (SE 17.4) compared with 21.3 (SE 3.6 ) mU/1 per h for control and guar gum meals respectively, $P<0.01$; areas under the plasma GIP curve 0-180 min: 2710 (SE 416) compared with 1760 (SE 256) ng/l per h, $P<0.01$ ).

Addition of guar gum to the carbohydrate meal did not significantly affect peak blood glucose levels (5.7 (SE 0.3) mmol/l compared with 5.0 (SE 0.3) mmol/l for control and guar gum meals respectively). In the second phase of the experiment $(90-180 \mathrm{~min})$ the addition of guar gum, in each case, prevented the fall in venous blood glucose to below fasting levels, thus effectively 'smoothing' the postprandial glucose curve compared with that of the control.

Plasma motilin was not measured after the carbohydrate meal, as circulating motilin levels fall after oral carbohydrate to levels below the sensitivity of the assay $(<50 \mathrm{ng} / \mathrm{l})$.

Protein meal. Plasma gastrin and GIP levels following ingestion of the protein meal are shown in Fig. 2. Postprandial GIP secretion was significantly decreased by addition of guar gum to the meal (area under the plasma GIP curve 0-150 min: 1744 (SE 118) compared with 1265 (SE 100) ng/l per h for control and guar gum meals respectively, $P<0.05$ ). In contrast, postprandial gastrin secretion was enhanced by the addition of guar gum (area under the plasma gastrin curve 0-120 min: 43 (SE 11) compared with 68 (SE 14) $\mathrm{mU} / 1$ per h for control and guar gum meals respectively, $P<0.005$ ). There was a highly significant negative correlation between peak plasma gastrin levels and the corresponding plasma GIP levels (Fig. 3$)$ in both control and guar gum meals $(r 0.80, P<0.01)$.

Plasma motilin levels rose postprandially but were similar after control and guar gum meals (basal motilin levels 108 (SE 18) ng/l; peak levels for control and guar gum meals 155 (SE 37) ng/l and 140 (SE 22) ng/l respectively). The area under the plasma motilin curve 0-150 min (control meal 142 (SE 34 ) $\mathrm{ng} / \mathrm{l}$ per h) was not significantly affected by addition of guar gum to the meal (guar gum meal 121 (SE 11) ng/l per h). Peak circulating levels of paracetamol were obtained $20 \mathrm{~min}$ after ingestion of both control and guar gum meals (Fig. 4). Gastric emptying, as assessed by the appearance and concentration of paracetamol in the circulation, was not affected by adding guar gum to the meal. Plasma glucose and insulin were not significantly elevated above basal levels at any time point after consumption of the protein meal. 


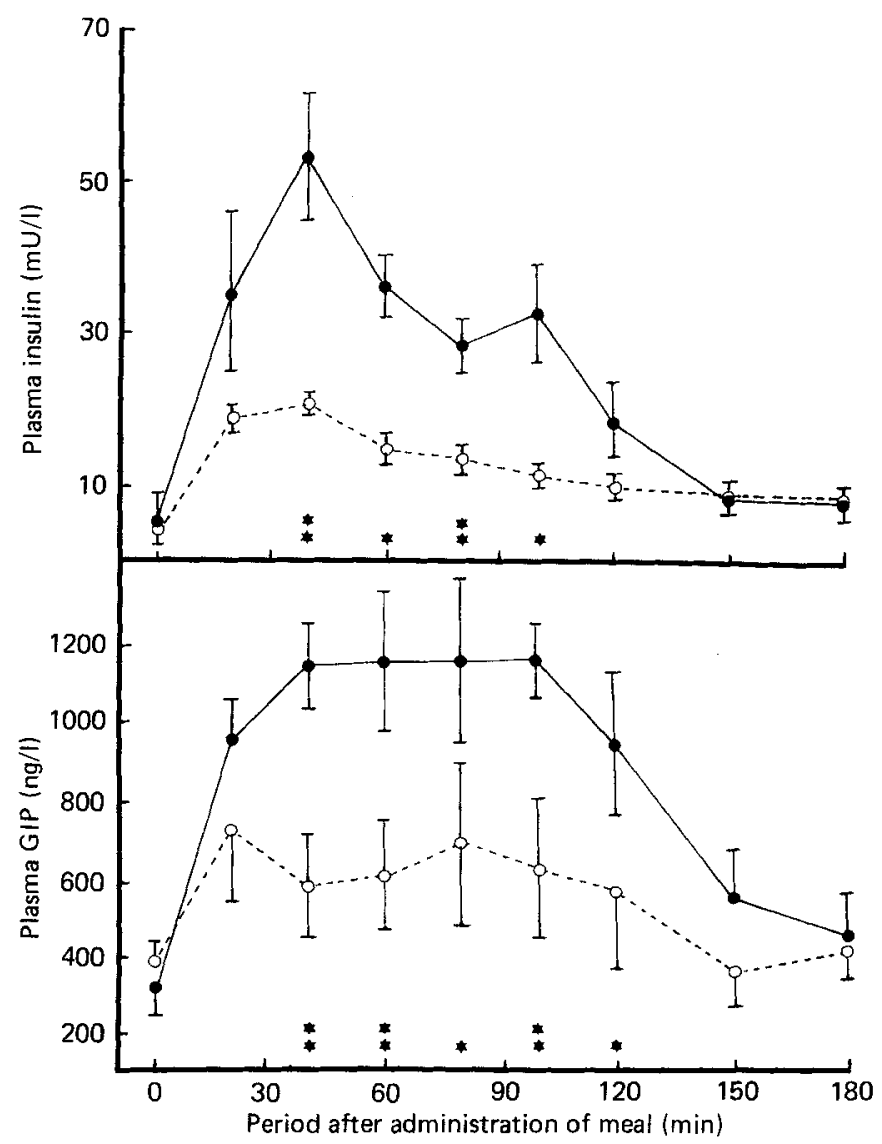

Fig. 1. Plasma insulin and gastric inhibitory polypeptide (GIP) concentrations (mean values with their standard errors represented by vertical bars) in five healthy subjects following a $50 \mathrm{~g}$ glucose meal with (O) or without (O) $5 \mathrm{~g}$ guar gum (* $\left.P<0.05,{ }^{* *} P<0.025\right)$.

Fat meal. Plasma GIP levels rose following oral fat but were not significantly affected by the presence of guar gum (area under plasma GIP curve 0-150 min: 1775 (SE 240) ng/1 per h compared with 1707 (SE 169) $\mathrm{ng} / \mathrm{l}$ per $\mathrm{h}$ for control and guar gum meals respectively). Plasma motilin levels were similarly unaffected - they rose from a mean basal level of 299 (SE 58) ng/l to 356 (SE 108) and 463 (SE 108) ng/l for control and guar gum meals respectively. The area under the plasma motilin curve $0-150 \mathrm{~min}$ (control meal 248 (SE 83 ) ng/l per h) was not significantly affected by addition of guar gum to the fat meal (guar gum meal 257 (SE 67) ng/l per h).

Plasma triglyceride levels did not rise significantly until $60 \mathrm{~min}$ following the fat load. The mean plasma triglyceride level at $120 \mathrm{~min}$ was significantly higher after the control than after the guar gum meal $(2.29$ (SE 0.6 ) mmol/1 compared with 1.49 (SE 0.3 ) mmol/1 for control and guar gum meals respectively, $P<0.05)$ but the area under the plasma triglyceride curve 60-150 min (control meal 0.78 (SE 0.6 ) $\mathrm{mmol} / \mathrm{l} \mathrm{per} \mathrm{h}$ ) was similar on the two occasions (guar gum meal 0.27 (SE 0.25 ) $\mathrm{mmol} / \mathrm{l}$ per h). Plasma light-scattering indices (as an index of postprandial chylomicronaemia) rose significantly following the meal but were unaffected by addition of guar gum.

Plasma paracetamol levels following the two fat meals were unaffected by guar gum 


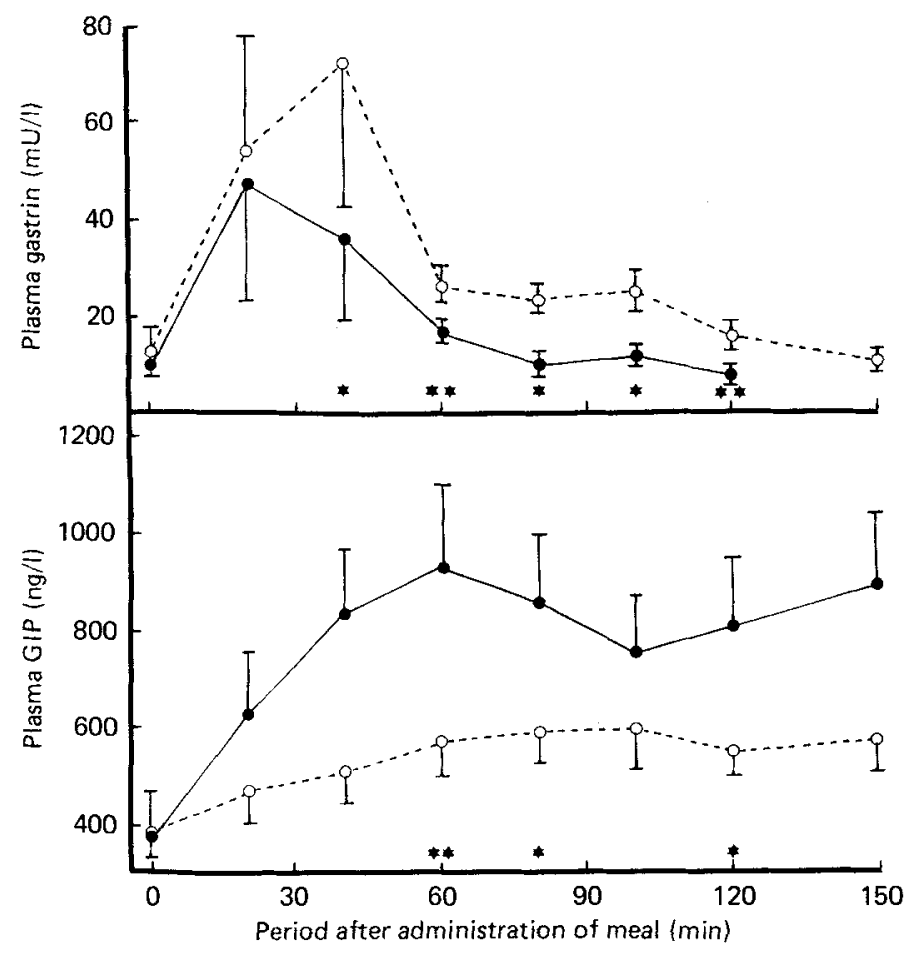

Fig. 2. Plasma gastrin and gastric inhibitory polypeptide (GIP) concentrations (mean values with their standard errors represented by vertical bars) in six healthy subjects following a meal containing $30 \mathrm{~g}$ protein with $(O)$ or without $(O) 5 \mathrm{~g}$ guar gum $(* P<0.05, * * P<0.025)$.

(Fig. 4). However, circulating paracetamol levels 20 min after ingestion of the fat meal were significantly lower than after the protein meal, and peak circulating levels were not attained until $40 \mathrm{~min}$ after meal ingestion. Plasma glucose and insulin levels were not significantly elevated above basal levels at any time point after consumption of the fat meal.

Buffering capacity of guar gum. The titration curves of a 5 and $10 \mathrm{~g}$ guar gum/l solution in water are shown in Fig. 5. Both concentrations of guar gum exhibited a buffering capacity between $\mathrm{pH} 2 \cdot 75$ and $5 \cdot 5$.

\section{DISCUSSION}

Addition of guar gum to an oral glucose load reduces the postprandial secretion of both GIP and insulin. These findings are in agreement with previous studies where addition of guar gum to a high carbohydrate solid or liquid meal was found to reduce GIP and insulin secretions in both normal and diabetic subjects (Morgan et al. 1979; O'Connor et al. 1981). The release of GIP from the gut in response to food may be related to the rate of active absorption of carbohydrates (Ebert \& Creutzfeldt, 1978; Sykes et al. 1980). Because guar gum increases the viscosity of solutions, it has been suggested that addition of guar gum to meals reduces the rate of diffusion of nutrients in the gut towards the absorptive surface (Caspary et al. 1980), although the total absorption of carbohydrate, as measured by urinary xylose excretion or breath hydrogen studies, is unchanged (Gassull et al. 1976; Leeds et al. 1978). GIP secretion is also related to the rate of gastric emptying and conditions where rapid gastric emptying occurs result in an increased GIP response (Creutzfeldt, 1981). 


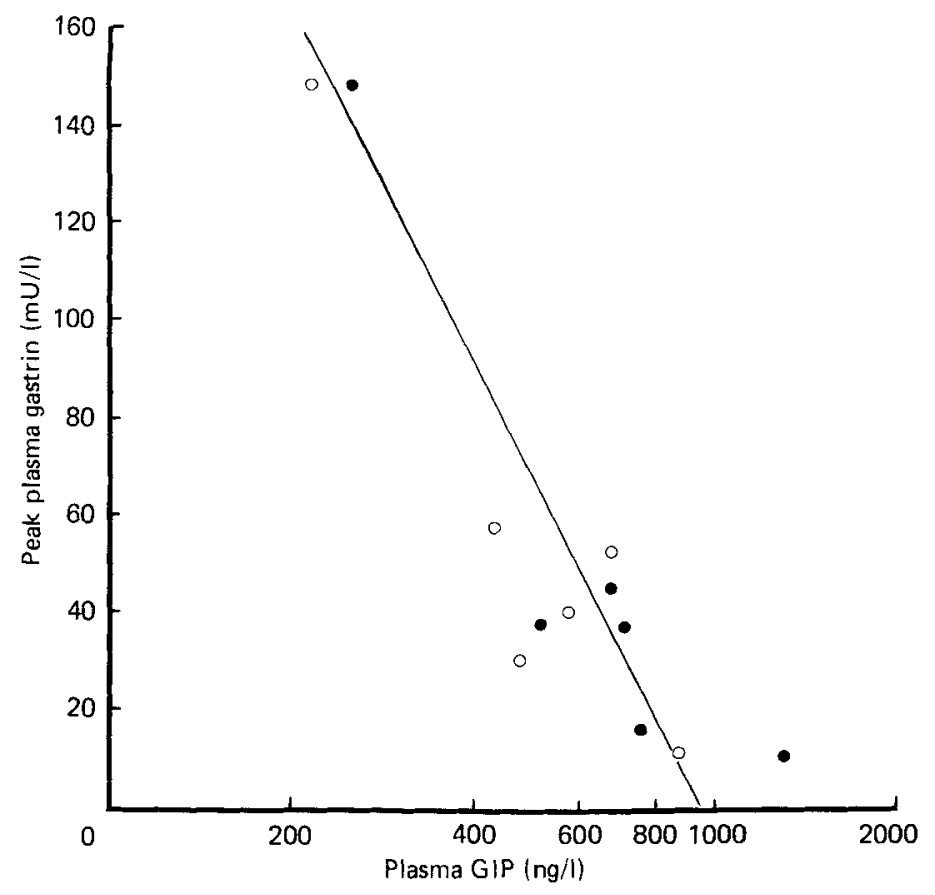

Fig. 3. Correlation between peak plasma gastrin concentrations and the corresponding plasma gastric inhibitory polypeptide (GIP) concentration in six healthy subjects following a meal containing $30 \mathrm{~g}$ protein with $(O)$ or without $(\bullet) 5 \mathrm{~g}$ guar gum $(r 0.80, P<0.01)$.

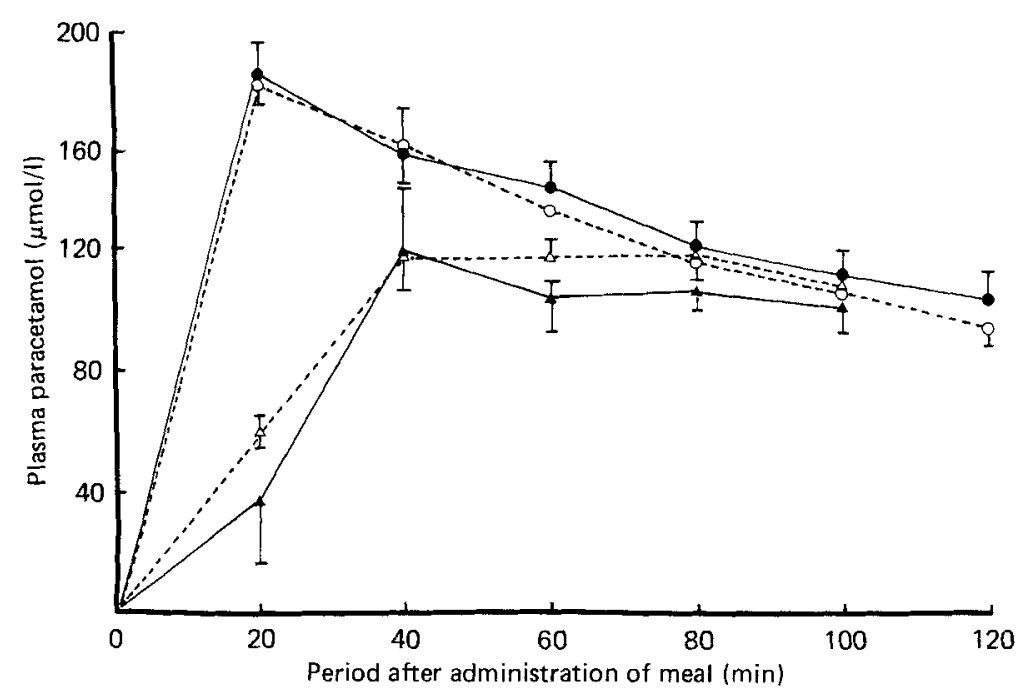

Fig. 4. Plasma paracetamol levels in healthy volunteers given fat $(\Delta, \Delta)$ or protein $(\boldsymbol{\bullet}, 0)$ meals either with $(\triangle, O)$ or without $(\boldsymbol{\Delta}, \mathbf{)})$ guar gum. Mean values with their standard errors represented by vertical bars, $n 6$ for protein meal, $n 8$ for fat meal. 


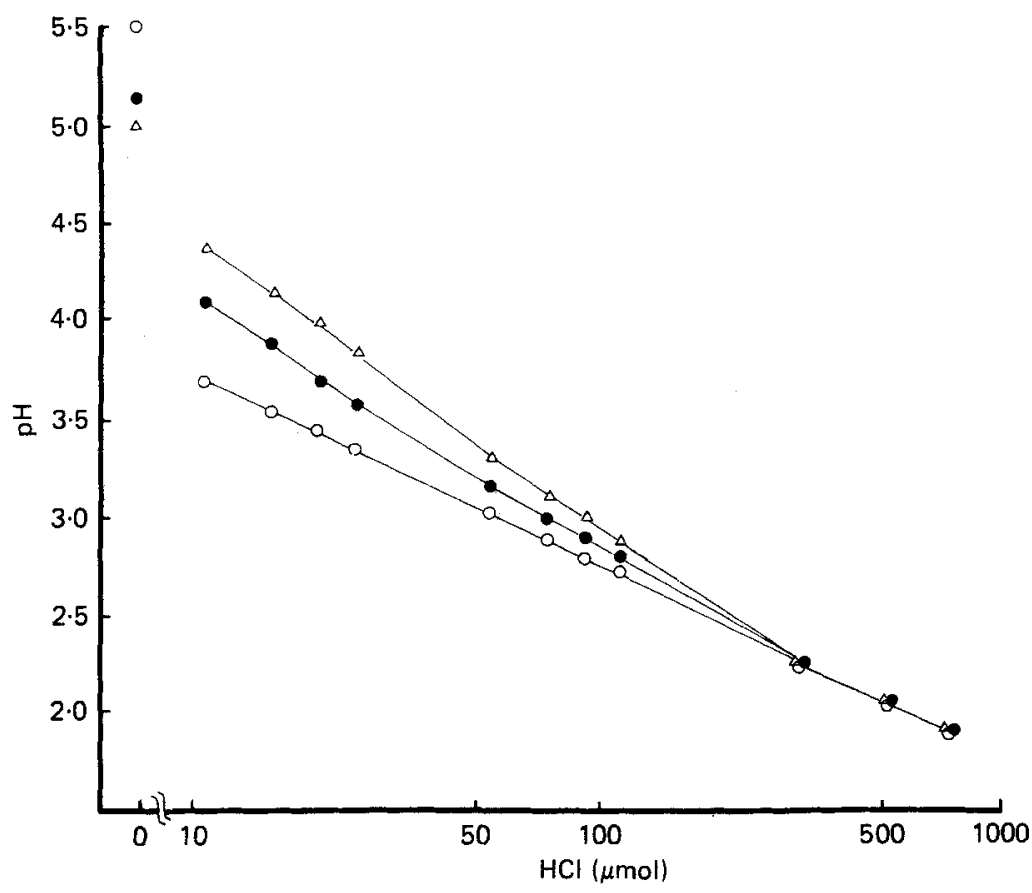

Fig. 5. Titration curves of suspensions of guar gum in $50 \mathrm{ml}$ tap water titrated against a solution of $0.1 \mathrm{M}$-hydrochloric acid. Mean values for triplicate estimations. $\bigcirc$, Tap water; $\bigcirc, 5 \mathrm{~g}$ guar gum $/ 1 ; \triangle$, $10 \mathrm{~g}$ guar gum $/ 1$.

Delayed gastric emptying in humans has been shown by adding guar gum (Wilmshurst \& Crawley, 1980) and a mixture of pectin and guar gum to a liquid meal (Holt et al. 1979), and guar gum alone delays gastric emptying of a liquid glucose meal in rats (Leeds et al. 1979) and pigs (Rainbird et al. 1984). GIP stimulates insulin secretion during hyperglycaemia (Brown et al. 1975), and the diminution in insulin response to test meals by the addition of guar gum is probably, at least in part, due to diminished GIP secretion.

Addition of guar gum to the protein meal also resulted in diminished postprandial GIP secretion. Intestinal absorption of free amino acids, as with glucose, takes place via active transport systems and therefore guar gum is also likely to slow down the rate of amino acid absorption, as has been shown in vitro (Elsenhans et al. 1980). In contrast, gastrin secretion was enhanced by adding guar gum to the protein meal. The mechanism by which guar gum exerts this effect is not clear.

The products of partial protein digestion provide the main stimulus to gastrin secretion in response to feeding. Gastrin secretion can be affected by both the rate of gastric emptying and the $\mathrm{pH}$ of stomach contents. Guar gum did not affect the rate of gastric emptying of the liquid phase of the protein meal as assessed by the appearance of paracetamol in the circulation. This method of assessing liquid gastric emptying has previously been found to correlate well with sequential scintiscanning techniques using ${ }^{113 m}$ In DTPA (Holt et al. 1979). In a subsequent study (J. A. Tredger et al. 1984) using ${ }^{99 m}$ Tc-labelled filter paper incorporated into minced beef, we have shown that guar gum does not affect solid-phase gastric emptying of the protein meal. The results in humans are in broad agreement with work carried out in pigs which showed that guar gum had no effect on the rate of gastric emptying of dry matter after consumption of a high-solid mixed meal (Rainbird et al. 1983). 
The differences in gastrin secretion observed cannot, therefore, be explained in terms of the length of time the food was in contact with the $G$ cells. In the present study, suspensions of guar gum in water exhibited a significant buffering capacity at $\mathrm{pH}$ values above 2.75 . Guar gum may possibly affect gastrin secretion by virtue of this buffering capacity since gastrin release is inhibited by acid acting directly on the antral G-cells.

Amino acid-stimulated gastrin release is $80 \%$ inhibited in normal man (Walsh et al. 1975) by a luminal $\mathrm{pH}$ of 2.5. Fasting antral $\mathrm{pH}$ is usually in the region of 1-3 (Dotevall, 1961) and rises after ingestion of a meal, the exact extent depending on the diluting and buffering capacity of the food, the volume of gastric acid secreted and the rate of gastric emptying. Guar gum may raise postprandial intragastric $\mathrm{pH}$, as has been found with other fibres (Tadesse, 1982), by virtue of its native buffering capacity thereby diminishing the contribution of the negative feed-back loop in inhibiting gastrin release.

Modulation of GIP secretion by guar gum provides an alternative explanation for the observed differences in gastrin secretion provoked by the control and guar gum meals. GIP was initially named for its capacity to inhibit gastric acid secretion (Brown et al. 1975) and exogenous GIP infusions have been shown to inhibit gastrin release (Villar et al. 1976; Arnold $e t$ al. 1978), the effect seemingly being mediated via an increase in gastric somatostatin secretion (McIntosh et al. 1979). Studies in dogs by Wolfe et al. (1983) using antiGIP antibodies have shown that GIP can function as a physiological inhibitor of gastric acid secretion through its effect on gastrin release. It is possible that attenuation by guar gum, of the GIP response to the protein meal, leads to an attenuated somatostatin response and hence unrestrained gastrin secretion. The highly significant negative correlation $(P<0.01)$ between circulating gastrin and GIP levels is consistent with this hypothesis.

GIP secretion was unaffected by the addition of guar gum to the fat meal. Although serum triglyceride levels are not the ideal indicators of fat absorption, especially in the first hour followingingestion, plasma triglyceride levels were similar after both guar-gum-supplemented and control meals, suggesting that other factors are more important in determining the rate of fat absorption. This is further supported by the failure to find any differences in the plasma light-scattering indices, a measure of chylomicronaemia, between the control and guar gum meals. These findings are in contrast to those of Jenkins (1978), who reported that guar gum was associated with an elevation in postprandial triglyceride levels after a mixed meal which he postulated was due to an effect of guar gum on postprandial chylomicronaemia.

Plasma paracetamol levels (which are an index of liquid gastric emptying rates) were similar after control and guar gum fat meals, although levels $20 \mathrm{~min}$ after ingestion of the fat meal were significantly lower than after ingestion of the protein meal. This suggests a slower rate of empyting for the fat meal and is consistent with previously published studies on the effect of meal composition on gastric emptying (Hunt \& Stubbs, 1975). It seems probable that guar gum is unable to exert any additional effect in delaying gastric emptying in this situation.

Motilin is released in response to oral fat and protein and is implicated in altering the rate of solid gastric emptying (Christofides et al. 1979 b). However, in the present study, guar gum did not affect the secretion of motilin in response to either fat or protein nor were any changes in gastric-emptying rate of the liquid phase detected.

The present study has indicated that guar gum, in amounts that would normally be consumed at each meal, affects the secretion of GIP and gastrin, both of which are implicated in the control of gastric acidity. As the use of guar gum in the therapy of diabetes and hyperlipidaemia is, of necessity, a long-term one, it would be desirable to ascertain whether the chronic use of guar gum is associated with changes in gastric acid secretion and whether guar gum can affect the rate of solid phase gastric emptying in humans. 


\section{REFERENCES}

Arnold, R., Ebert, R., Creutzfeldt, W., Becker, H. D.\& Börger, H. (1978). Scandinavian Journal of Gastroenterology 13 (Suppl. 48), 11.

Blackburn, N. A., Redfern, J. S., Jarjis, H., Holgate, A. M., Hanning, I., Scarpello, J. H. B., Johnson, I. T. \& Read, N. W. (1984). Clinical Science 66, 329-336.

Brown, J. C., Dryburgh, J. R., Ross, S. A. \& Dupre, J. (1975). Recent Progress in Hormone Research 31, 487-532.

Caspary, W. F., Elsenhans, B., Süfke, U., Ptok, M., Blume, R., Lembcke, B. \& CreutzfeIdt, W. (1980). In Frontiers in Hormone Research, vol, 7, pp. 202-217 [W. Creutzfeldt, editor]. Basel: Karger.

Christofides, N. D., Bloom, S. R., Besterman, H. S., Adrian, T. E. \& Ghatei, M. A. (1979a). Gut 20, $102-106$.

Christofides, N. D., Modlin, I. M., Fitzpatrick, M. L. \& Bloom, S. R. (1979 b). Gastroenterology 76, $903-907$.

Creutzfeldt, W. (1981). In Gut Hormones, 2nd ed., pp. 533-540 [S. R. Bloom and J. M. Polak, editors]. London: Churchill Livingstone.

Dotevall, G. (1961). Acta Medica Scandinavica 170, 59-63.

Dryburgh, J. R. \& Brown, J. C. (1975). Gastroenterology 68, 1169-1176.

Ebert, R. \& Creutzfeldt, W. (1978). In Gut Hormones, pp. 294-300 [S. R. Bloom, editor]. London: Churchill Livingstone.

Elsenhans, B., Süfke, U., Blume, R. \& Caspary, W. F. (1980). Clinical Science 59, 373-380.

Gassull, M. A., Goff, D. V., Haisman, P., Hockaday, T. D. R., Jenkins, D. J. A., Jones, K., Leeds, A. R. \& Wolever, T. M. S. (1976). Journal of Physiology (London) 259, 52-53.

Holt, S., Heading, R. C., Carter, D. C., Prescott, L. F. \& Tothill, P. (1979). Lancet i, 636-639.

Hunt, J. N. \& Stubbs, D. F. (1975). Journal of Physiology (London) 245, 209-225.

Jenkins, D. J. A. (1978). In International Conference on Atherosclerosis, pp. 173-176 [L. A. Carson, R. Paoletta, C. R. Sirton and G. Weber, editors]. New York: Raven Press,

Jenkins, D. J. A., Hockaday, T. D. R., Howarth, R., Apling, E. C., Wolever, T. M. S., Leeds, A. R., Bacon, S. \& Dilawari, J. (1977b). Lancet ii, 779-780.

Jenkins, D. J. A., Leeds, A. R., Gassull, M. A., Goff, D. V., Wolever, T. M. S. \& Alberti, K. G. M. M. (1977a). Proceedings of the Nutrition Society 36, 44A.

Jenkins, D. J. A., Leeds, A. R., Slavin, B., Mann, J. \& Jepson, E. M. (1979). American Journal of Clinical Nutrition 32, 16-18.

Jenkins, D. J. A., Leeds, A. R., Wolever, T. M. S., Goff, D. V., Alberti, K. G. M. M., Gassull, M. A. \& Hockaday, T. D. R. (1976), Lancet ii, 172-174.

Jenkins, D. J. A., Wolever, T. M. S., Leeds, A. R., Gassull, M. A., Haisman, P., Dilawari, J., Goff, D. V., Metz, G. L. \& Alberti, K. G. M. M. (1978). British Medical Journal i, 1392-1394.

Jenkins, D. J. A., Wolever, T. M. S., Taylor, R. H., Reynolds, D., Nineham, R. \& Hockaday, T. D. R. (1980). British Medical Journal 280, $1353-1354$.

Leeds, A. R., Bolster, N. R., Andrews, R. \& Truswell, A. S. (1979). Proceedings of the Nutrition Society 38, 44A.

Leeds, A. R., Bolster, N. R. \& Truswell, A. S. (1978). Proceedings of the Nutrition Society 37, 89A.

McIntosh, C. H. S., Pederson, R. A., Koop, H. \& Brown, J. C. (1979). In Gut Peptides, pp. 100-104 [A. Miyoshi, editor]. Amsterdam: Elsevier North Holland.

Morgan, L. M., Goulder, T. J., Tsiolakis, D., Marks, V. \& Alberti, K. G. M. M. (1979). Diabetologia 17, 85-89.

Morgan, L. M., Morris, B. A. \& Marks, V. (1978). Annals of Clinical Biochemistry 15, 172-177.

O'Connor, N., Tredger, J. \& Morgan, L. M. (1981). Diabetologia 20, 612-615.

Rainbird, A. L., Low, A. G. \& Sambrook, I. E. (1983). Proceedings of the Nutrition Society 42, 24A.

Rainbird, A. L., Low, A. G. \& Sambrook, I. E. (1984). Proceedings of the Nutrition Society 43, 28 A.

Sykes, S., Morgan, L. M., English, J. \& Marks, V. (1980). Journal of Endocrinology 85, 201-207.

Tadesse, K. (1982). Journal of Physiology 322, 102P-103P.

Tredger, J. A., Morgan, L. M., Peke, J. \& Marks, V. (1984). Regulatory Peptides 9, 350.

Villar, H. V., Fender, H. R., Rayford, P. L., Bloom, S. R., Ramus, N. I. \& Thompson, J. C. (1976). Annals of Surgery 184, 97-102.

Walsh, J. H., Richardson, C. T. \& Fordtran, J. S. (1975). Journal of Clinical Investigation 55, $462-468$.

Wilmshurst, P. \& Crawley, J. C. W. (1980). British Journal of Nutrition 44, 1-6.

Wolfe, M. M., Hocking, M. P., Maico, D. G. \& McGuigan, J. E. (1983). Gastroenterology 84, 941-948. 